\title{
Minimum wages, youth employment and spatial spillovers: New evidence for Spain
}

\author{
Jordi López-Tamayo ${ }^{1} \cdot$ Celia Melguizo² $^{2} \cdot$ Raúl Ramos $^{1}$
}

Received: 2 September 2020 / Accepted: 4 October 2021 / Published online: 27 November 2021

(c) The Author(s) 2021

\begin{abstract}
The effect of minimum wages increases on youth employment level has been extensively analysed, but recent contributions have highlighted the potential bias in these studies due to neglected spatial autocorrelation in the considered relationship. This paper contributes to this scarce literature by providing novel evidence for a country with very low interregional mobility. The aim is to see if the bias of neglecting spatial dependence acts in a similar direction than in the few studies for the United States and if this bias explains the low elasticity of youth employment to minimum wages in Spain compared to the international literature. Our results show the relevance of spatial spillovers in the Spanish regional labour markets, but after correcting for the bias, we do not find a significant negative elasticity of youth employment to minimum wages, with the only exception of those between 16 and 19 years old.
\end{abstract}

Keywords Minimum wage $\cdot$ youth employment $\cdot$ Spanish regions $\cdot$ spatial spillovers

JEL codes $\mathrm{J} 31 \cdot \mathrm{E} 23 \cdot \mathrm{R} 1$

\section{Background and objectives}

The analysis of the effect of the minimum wage on youth employment is interesting since, in the developed economies, they are generally those with lower wages and higher levels of unemployment. In fact, the social and economic impact of the Great

Celia Melguizo

celia.melguizo@ucv.es

Jordi López-Tamayo

jlt_lopez@ub.edu

Raúl Ramos

rramos@ub.edu

1 AQR- IREA, University of Barcelona (UB), Barcelona, Spain

2 AQR- IREA, University of Barcelona (UB), Barcelona, Spain 
Recession on youth has been particularly strong in these countries. Job creation has stagnated since the beginning of the global financial crisis and young people, particularly those entering the labour market for the first time, have found much more difficulties to find stable and well-paid jobs. For this reason, governments in these countries are using minimum wages as one of the main tools to fight against inwork-poverty (Holtemöller \& Pohle, 2019; Majchrowska \& Strawiński, 2018), especially for youth, but at the same time, the impact of these policies on youth employment levels is uncertain.

Our objective is to provide new evidence about the impact of minimum wages on youth employment rates for Spain, a labour market characterised by a high level of rigidity and where minimum wages have substantially increased during the last recent years.

There is a substantial body of empirical evidence on the effects of the minimum wage on youth employment. Authors such as Neumark and Wascher (2004) or Dolton and Rosazza-Bondibene (2012), among others, have found a negative relation between employment and minimum wages for young people between 15 and 24 years. However, considering 328 estimates from different 15 countries covering the period running from 1990 to 2015 and applying meta-analytical techniques, O'Higgins and Moscariello (2017) have concluded that there is no significant effect of minimum wage on youth unemployment. ${ }^{1}$ This result contrasts with the prediction of standard neoclassical theory that establishes that when the minimum wage is raised, labour demand reduces and at the same time, labour supply increases. The result is a reduction in the level of employment (or hours worked) and an increase in unemployment. However, as Schmitt (2013) highlights, increases in minimum wage could also be adjusted by firms through other channels such as increases in the prices of products or through a reduction of social benefits that could alleviate the negative effects on employment. Moreover, an increase in the wage of workers affected by minimum wages -with lower purchasing power- could favour consumption and increase the labour demand for local companies. In fact, the dynamic monopsony model also states that frictions in the labour market, such as those related to hiring new workers and the difficulties associated to find a job, especially for some groups, suppose that the labour market operates with vacant positions. An increase in the minimum wage could increase supply and may lead to positive effects on employment at macroeconomic level as it improves the quality of matching and reduces unfilled vacancies.

These mechanisms, however, are clearly associated to spatial aspects of the labour market that have been systematically ignored in the literature. Previous studies of the minimum wage have neglected the issue of spatial dependence. This has potentially led to biased, inconsistent, and inefficient parameter estimates. In fact, to the best of our knowledge, the only studies that account for the fact that minimum wages

\footnotetext{
1 Interestingly, similar results have been obtained by meta-analysis considering the impact of the minimum wage on overall employment (see Bellman \& Wolfson, 2014; Card \& Krueger, 1995; Doucouliagos \& Stanley, 2009; Leonard et al., 2014) and similar conclusions have been obtained in the recent narrative review by Dube (2019).
} 
and youth employment could be correlated across political boundaries are Kalenkoski and Lacombe $(2008,2013)$. These authors argue that "this correlation may exist whether a change in the effective minimum wage in a state (i.e., the maximum of the state and federal minimum wages) affects employment not only in its own state but also in other neighbouring states". In case that minimum wage is increased in one state, workers in a neighbouring state without an increase may decide to cross the border to benefit from this increase. If this happens, the overall effect of the minimum wage increase should also consider the reduction in employment in the neighbouring state in addition to the potential reduction in the state that increased its minimum wage. This indirect effect can be captured by applying spatial econometric techniques. The results by Kalenkoski and Lacombe $(2008,2013)$ for the US states applying these techniques allows them to conclude that ignoring spatial correlation biases the estimates of the effect of minimum wages on youth employment (both in cross-sectional or panel data settings). In their case, the obtained elasticity after controlling for spatial dependence is higher than the one obtained when using a standard panel data model.

This research contributes to this scarce literature by considering spatial effects in the relationship between minimum wage and employment in Spain, a country with relatively low mobility of young workers (Ramos \& Royuela, 2017) and with a high increase in the minimum wage during the considered period. Between 2010 and 2018, an internal wage devaluation process took place in Spain but, at the same time, minimum wages measured by the Kaitz Index, the ratio of the minimum wage to average wages (Kaitz, 1970) increased substantially. In particular, this index increased from values close to $41 \%$ in 2006 to $50 \%$ in 2018 . Although in Spain there is no territorial differentiation of the minimum wage in nominal terms, the existence of different regional price levels and inflation rates (Costa et al., 2015, 2019) makes the real magnitude of the Kaitz index territorially heterogeneous varying at the provincial level between $30 \%$ and almost $70 \%$. Therefore, in our work, we take profit of the spatial variations in the Kaitz index and youth employment rates during the recession and subsequent recovery in Spain to provide new evidence of the relevance of spatial spillovers in the labour market in a low mobility country and how omitting spatial dependence in the analysis could bias the obtained results. In fact, there is a wide literature showing the relevance of spatial spillovers between regional labour markets in Spain. A part of the seminal works by López-Bazo et al. (2002, 2005) and, more recently, López-Bazo and Motellón (2012), Cuéllar-Martín et al. (2019) show clear evidence of the importance of spatial effects to explain the regional evolution of employment in Spain while Martín-Román et al. (2020) perform a similar analysis for participation rates. Our results are well in line with this previous literature: spatial spillovers are relevant to explain youth employment rates and we provide evidence on how omitting spatial dependence could bias the estimates of the elasticity of interest. After controlling for spatial dependence, we find no evidence of a significant negative effect of minimum wages on total employment between 2006 and 2018, but only on youth aged between 16 and 19 years. Dube et al. (2010) use a different approach identifying policy discontinuities on minimum wages at state borders as part of the modelling strategy, but the conclusion is the same: not accounting for local economic conditions tend to produce spurious 
negative effects due to spatial heterogeneities in employment trends that are unrelated to minimum wage policies.

The rest of the paper is organised as follows. First, in Section 2 we present the data and the methodology used for our empirical analysis. In Section 3 we present and discuss the obtained results and, finally, we summarise the main findings and conclusions of our research.

\section{Data and methodology}

\section{Data}

The analysis of the influence of minimum wages on youth employment taking into account the spatial dynamics requires information disaggregated at provincial level (NUTS 3). Province is the territorial administrative unit that is generally considered the one closest to the concept of local labour markets. In our analysis, we take into account 46 of the 52 Spanish provinces ${ }^{2}$ and autonomous cities.

We have used several data sources to carry out our empirical analysis ${ }^{3}$. The employment data has been drawn from the Labour Force Survey (Encuesta de Población Activa, EPA). We resort to the microdata of this survey because we need the information disaggregated at provincial level and for heterogeneous groups in terms of age and gender. We also use the EPA microdata to obtain information about the level of temporality and also part-time employment, which are control variables in our analysis. EPA also reports information on the industry composition of employment to construct the Theil Index and also the data to obtain the regional human capital indicator, which is calculated taking into account the Instituto Valenciano de Investigaciones Económicas (IVIE) methodology. With regards to the information on wages, the Spanish Agency of Tax Administration (Agencia Española de Administración Tributaria, AEAT) provides the annual wage of the average employee ${ }^{4}$. Provincial GDP is obtained from the Spanish Regional Accounts (Contabilidad Regional de España, CRE). The data of total population and population by age groups is obtained from the Municipal Register, meanwhile data on provincial surface, which will be used to obtain the population density, is obtained from the Statistical Yearbook of the National Institute of Statistics (Instituto Nacional de Estadística, INE).

\footnotetext{
${ }^{2}$ Ceuta and Melilla autonomous cities have been removed from sample given the small sample size of the Labour Force Survey and, therefore, the low statistical representativeness of the calculated indicators for these provinces. Besides, Navarra, Álava, Guipúzcoa and Vizcaya provinces are also removed since they are not included in the statistics of the Tax Agency used to approximate average wage levels at the regional level.

3 Table A1 in the Appendix provides a detailed description of the different data sources. Table A2 shows basic descriptive statistics for the variables considered in our analysis.

4 While similar information can also be obtained from Spanish Regional Accounts, provincial data from this source is only available until 2011 not allowing to consider the recent trends in the evolution of minimum wage in Spain.
} 


\section{Empirical Strategy}

In order to assess whether the minimum wage has had any impact on the employment rate in Spanish for the period 2006-2018, we specify the following model:

$$
\begin{gathered}
\ln \left(E R_{i t}\right)=\tau \ln \left(E R_{i t-1}\right)+\rho W \ln \left(E R_{i t}\right)+\delta \ln \left(\text { Kaitz }_{i t}\right)+\beta X_{i t}+\gamma \text { WKaitz }_{i t} \\
+\theta W X_{i t}+\mu_{i}+\alpha_{t}+u_{i t} \\
u_{i t}=\lambda W u_{i t}+\varepsilon_{i t}
\end{gathered}
$$

where:

- $\ln \left(E R_{i t}\right)$ is the natural logarithm of the employment rate in period t corresponding to the province i differentiated by age $\left[\ln (E R), \ln \left(E R \_1619\right), \ln \left(E R \_2024\right)\right.$, $\left.\ln \left(E R \_2529\right)\right]$

- $\ln \left(\right.$ Kaitz $\left._{i t}\right)$ is the natural logarithm of the Kaitz index, which is the relation between the minimum wage and the average nominal wage in each province

- $X_{i t}$ is a set of additional controls related to the evolution of employment rates

- $W$ represents the matrix of spatial weights based on spatial contiguity between provinces $^{5,6}$

- $\tau, \rho, \delta, \beta, \gamma, \theta, \lambda$ are the coefficients of the variables of the model

- $\mu_{i}$ captures provincial fixed effects

- $\alpha_{\mathrm{t}}$ captures time fixed effects

- $u_{i t}$ is a random error term that could also follow a spatial autoregressive pattern subjected to idiosyncratic shocks captured by $\varepsilon_{\text {it }}$

Equation (1) represents a rich family of spatial models that have been considered in the literature (Anselin, 2003; Elhorst, 2014; Fingleton, 2008a, b; LeSage \& Pace, 2007). Depending on the different types of spatial interactions that are considered in the specification, we estimate the following models:

- Spatial Autorregresive Combined Model (SAC) allowing spatial interactions in the endogenous variable (WY) and in the error term (WU), but not in covariates,

- Spatial Durbin Model (SDM) allowing spatial interactions in the endogenous variable (WY) and in covariates (WX), but not in the error term (WU),

- Spatial Autorregresive Model (SAR) allowing spatial interactions in the endogenous variable (WY), but not in covariates or in the error term,

\footnotetext{
5 The results shown in the main text are based on a spatial contiguity matrix. Similar conclusions have been obtained by using a spatial matrix based on the inverse of the distance and a k-nearest neighbours spatial matrix using information from the 5 nearest ones $-\mathrm{knn}(5)$. Tthe haversine distance has been used, which is the one recommended when the spatial units are located on the surface of the earth and the variables represent these spatial locations (Drukker et al., 2013). Detailed results for descriptive evidence and econometric analysis are shown in tables and figures in the appendix.

6 Three spatial units in our analysis are islands: Balearic Islands and Canary Islands (formed by two provinces). In this case, we have assumed that these provinces are "contiguous" to the nearest province: Valencia in the case of Balearic Islands and Cadiz in case of the Canary Islands.
} 
- Spatial Error Model (SEM) allowing spatial interactions only in the error term (WU).

Instead of adopting a model selection strategy between these different specifications, we present all the results in order to check if the consideration of various types of spatial spillovers modifies the effect of our covariate of interest, the Kaitz index. It is worth mentioning that Eq. (1) also introduces the employment rate lagged one period in order to capture the existence of hysteresis in the dynamics of employment (see, for instance, Mota et al., 2012).

Different variables that are likely to affect employment rates have been considered as additional controls $\left(X_{i t}\right)$. In particular, we include the growth rate of the provincial gross domestic product (GDP) lagged one period (in order to avoid potential endogeneity $)^{7}$, the Theil index of sectoral specialisation based on 5 activity sectors (agriculture, manufacturing, construction, private and public services), the population density, the part-time employment rate, the temporary employment rate and the average number of years of schooling by province (a human capital indicator) computed following the methodology by IVIE using microdata from the Spanish Labour Force Survey. As previously mentioned, we have also introduced time fixed effects in order to capture the common shocks that all provinces have suffered during each year of the considered period. Last, provincial fixed effects are also introduced to take into account provinces' specificities not captured by the rest of variables.

Equation (1) has been estimated for the employment rate and for the youth employment rate distinguishing by age groups (16-19 20-24, and 25-29). The consideration of the overall employment rate is for comparison purposes only as our main interest is in youth employment rates. However, as young people are supposed to be more geographically mobile, it is interesting to see whether we find different results for both groups.

\section{Results and discussion}

Figure 1 shows some descriptive evidence on the relationship between the Kaitz index and the employment rate for the different groups of workers considered in our analysis. A clear negative relationship is observed in all cases, although the correlation is slightly stronger for all workers than for younger groups.

Figure 2 represents the values corresponding to Global Moran's I using a contiguity spatial matrix. Data evidence a strong positive spatial dependence with a high stability over time for the total employment rate, but a stronger variation for youth employment rates, particularly for those aged 16-19. Figure 3 show the results obtained using the local statistics of Moran's I for the employment rate. It is interesting to see that for total employment rate two clear geographical areas can be

\footnotetext{
7 Several works within the regional Okun's law literature such as Bande and Martín-Román (2018) and Porras-Arena and Martín-Román (2019) have highlighted the need to control for differences in economic activity when analysing the developments of regional labour markets in Spain.
} 
a) Total Population

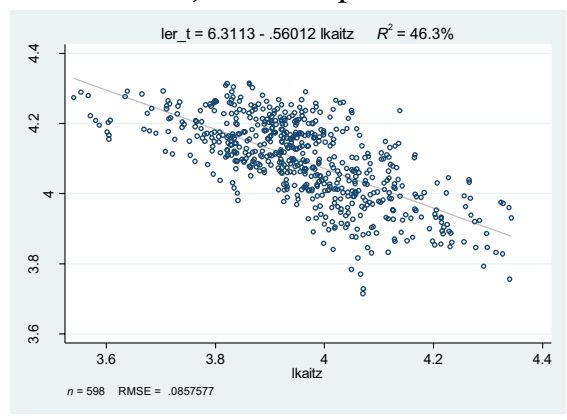

c) Youth $20-24$

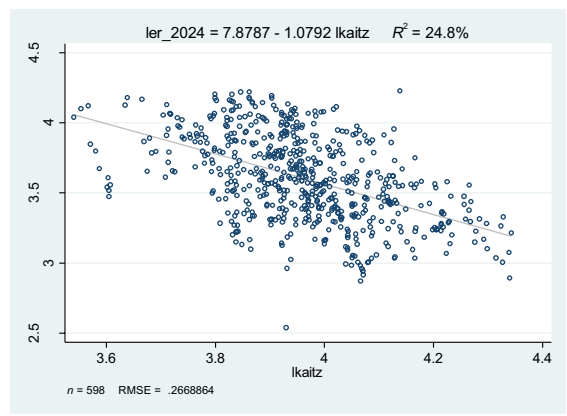

b) Youth $16-19$

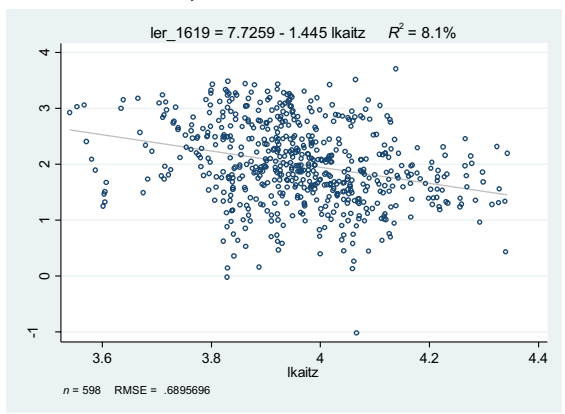

d) Youth 25-29

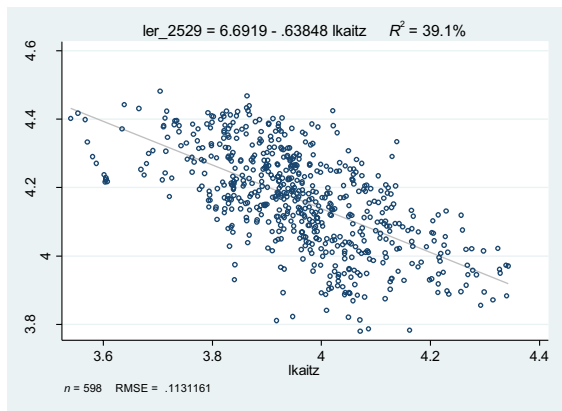

Fig. 1 Relationship between the Employment Rate and the Kaitz Index a) Total Population b) Youth 16-19 c) Youth 20-24 d) Youth 25-29

observed: one located in the south-west and in the north-east of Spain and another one covering the rest of the country. The picture seems to be quite stable over time. However, when looking at youth employment rates, the pattern is different with higher values of the statistics in Northern regions and lower values in Southern ones. This is particularly true for the employment rate for those aged 16-19. This exploratory analysis confirms the existence of spatial spillovers in the employment rate that seem to be different depending on the considered age group. These results reinforce the idea that we cannot omit the potential existence of spatial spillovers when analysing the impact of minimum wages on regional employment rates ${ }^{8}$.

Tables 1 shows the results of estimating Eq. (1) for the employment rate under different specifications. Column 1 shows the results of estimating a model assuming a linear relationship between the log of the Kaitz Index and the log of the employment rate controlling for the effect of the considered covariates but without spatial effects. The next columns contain the results of estimating the different types of spatial models described in the methodology section. In particular, the results shown

\footnotetext{
8 Similar conclusions are obtained when using the inverse of distance or the $\operatorname{Knn}(5)$ spatial matrixes as shown in figures A1 to A4 in the appendix.
} 


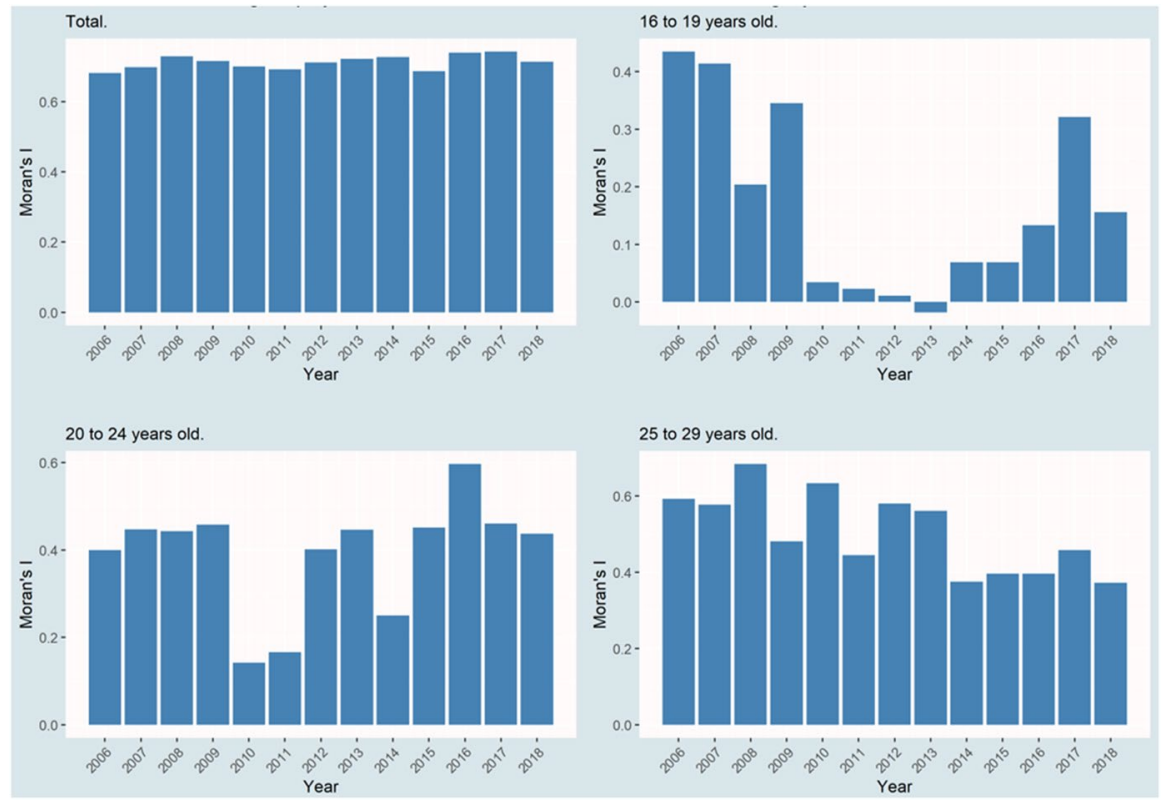

Fig. 2 Global Moran's I for the log of Employment Rate Contiguity spatial matrix

here have been obtained using a spatial contiguity matrix ${ }^{9}$, while those obtained using the inverse of distance spatial matrix and the $\operatorname{Knn}(5)$ spatial matrix are shown in Tables 2, 3, 4 and 5 in the appendix. Results are very similar to the ones described here based on Table 1 .

In all specifications, the coefficient associated to the lagged value of the employment rate is positive and statistically significant at the usual levels with values around 0.5 for total population and between 0.2 and 0.3 for youth, values that are well in line with the values found in the previous literature. The coefficient associated to the Kaitz index is not statistically significant at the usual levels for total employment, while regarding specific age groups, the only group that seems to be affected by the increase in minimum wages when no spatial spillovers are considered is the group aged 24-29, where the Kaitz index is negative and statistically significant at the $10 \%$ level with an elasticity close to -0.3 , a value that is well in line with those found in the international literature. In particular, in their analysis for 17 OECD countries between 1975 and 2000, Neumark and Wascher (2004) obtained an elasticity of the employment rate to the Kaitz index of -0.13 for youth between 15 and 24 years old and -0.18 , when the 15 to 19 population aged group was considered. Dolton and Rosazza-Bondibene (2012), in

\footnotetext{
9 It is worth mentioning that the values of the Moran's I statistics for the residuals of the cross-sectional estimates of Eq. (1) do not reject the existence of spatial autocorrelation in the considered relationship. Detailed results are available from the authors on request.
} 
a) Total Population

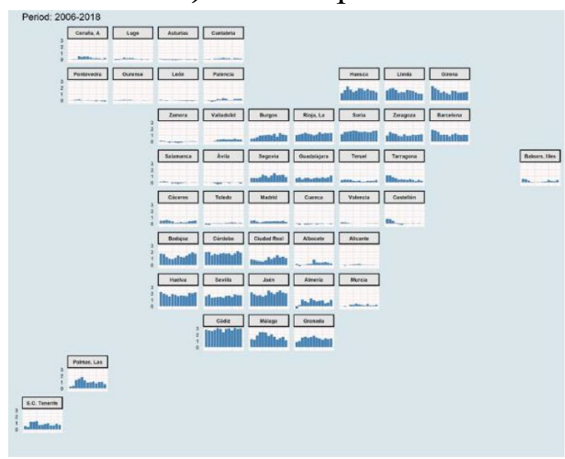

c) Youth 20-24

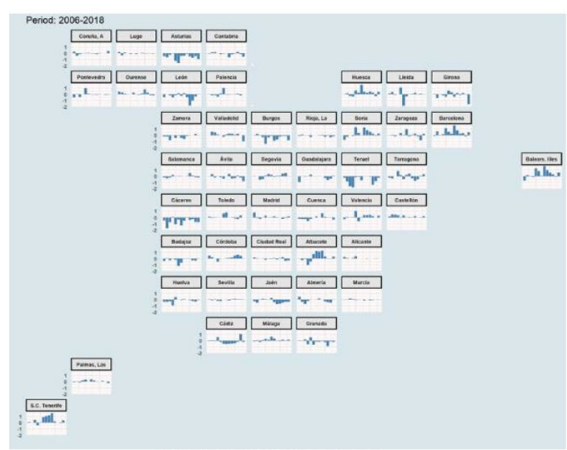

b) Youth 16-19

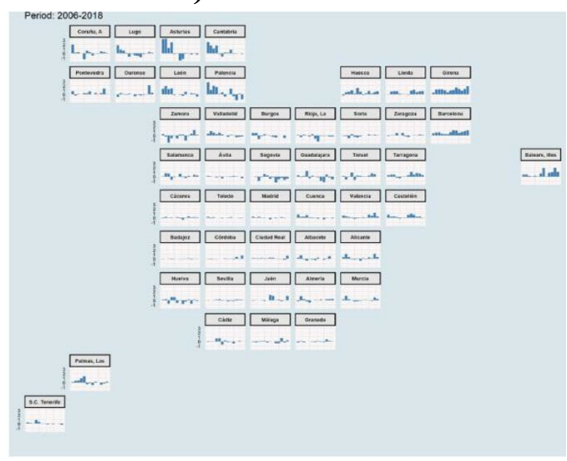

d) Youth 25-29

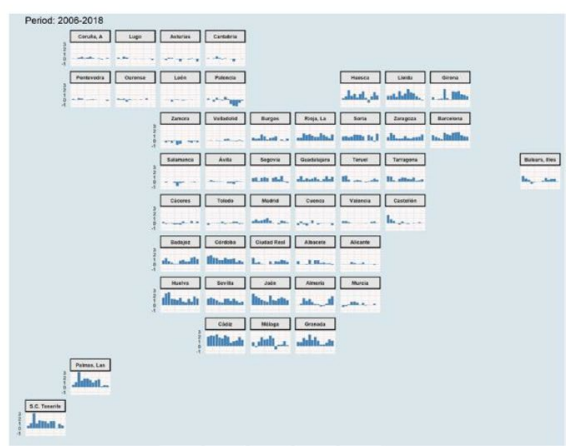

Fig. 3 Local Moran's I for the log of Employment Rate Contiguity spatial matrix a) Total Population b) Youth 16-19 c) Youth 20-24 d) Youth 25-29

their analysis for 33 OECD countries for the 1971-2009 period, obtained a minimum wage coefficient of -0.20 for youths between 15 and 24 years old. Analysing $18 \mathrm{EU}$ member states between 1996 and 2011, Laporsek (2013) found much higher elasticities ranging from- 0.29 to -0.38 for the 20-24-year-old age group and from -0.74 to -1.05 for the 15-19-year-old age group. Arpaia et al. (2017) obtained a negative elasticity between -0.13 and -0.20 for workers between 20 and 24 in the European Union (EU) member states. Last, analysing Canadian provinces, Rybczynski and Sen (2018) found an elasticity around -0.04 for youth aged 18-19 years old.

But, to what extent the previous results are biased by the fact we are neglecting spatial dependence when estimating the relationship between employment rates and minimum wages? After considering the effect of spatial spillovers, no effect of the minimum wage is found for the age group 24-29. The opposite situation is observed for youth between 16 and 19 years old. In fact, this is the age group when less-skilled workers face their school-to-work transition and, as expected, it seems to be the one that has been more damaged by the relative increase of minimum wages during the recession. While the Kaitz index was not statistically 


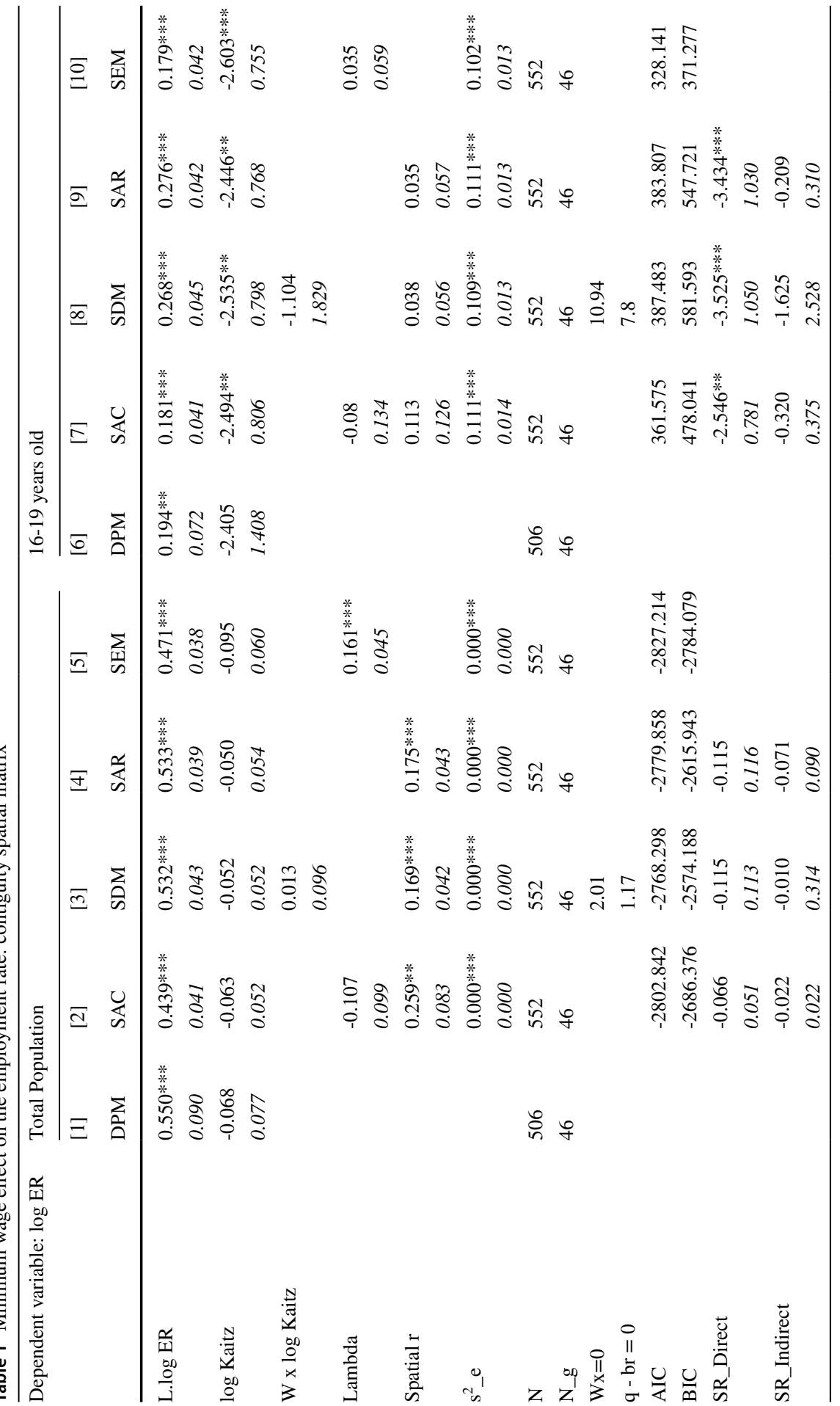




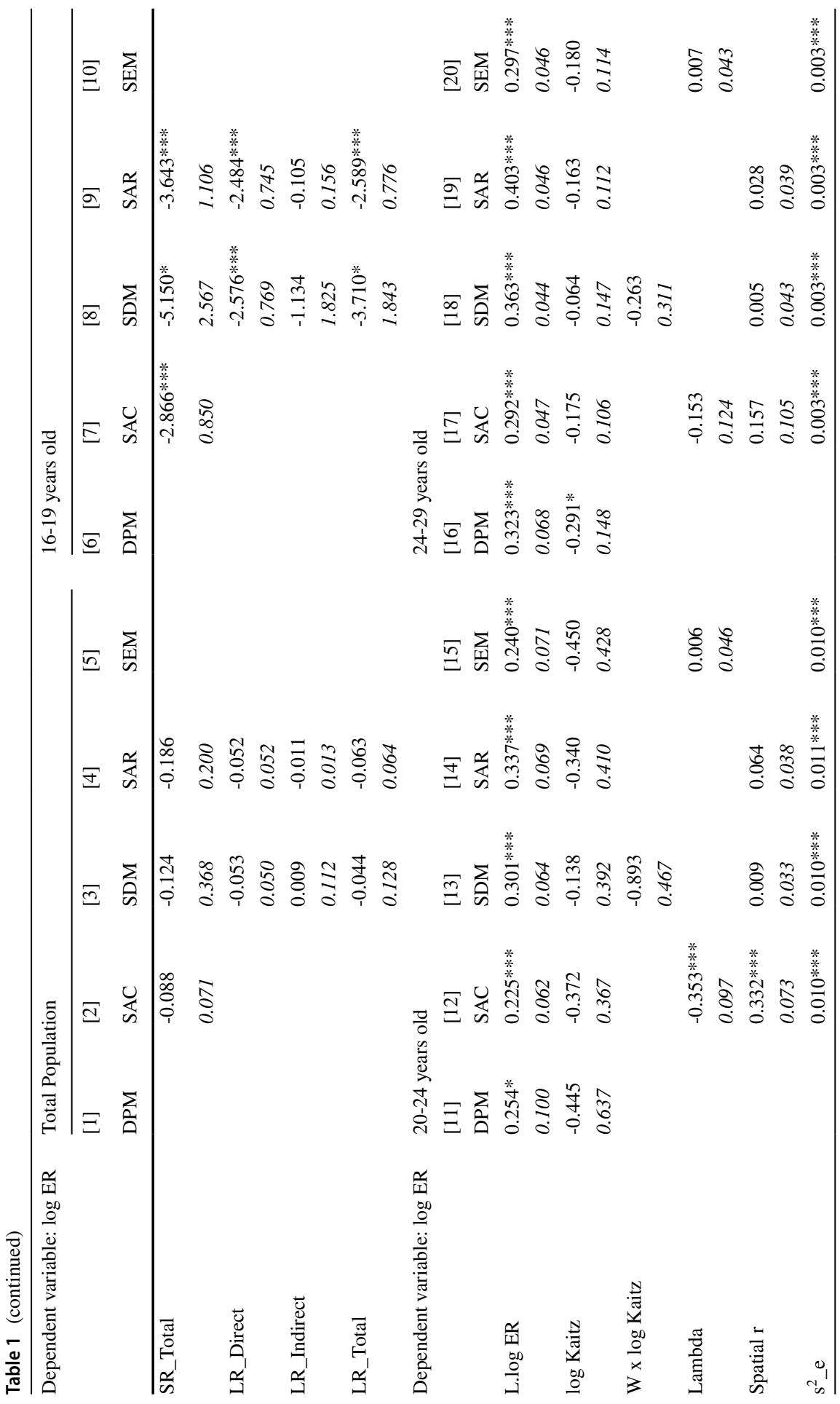




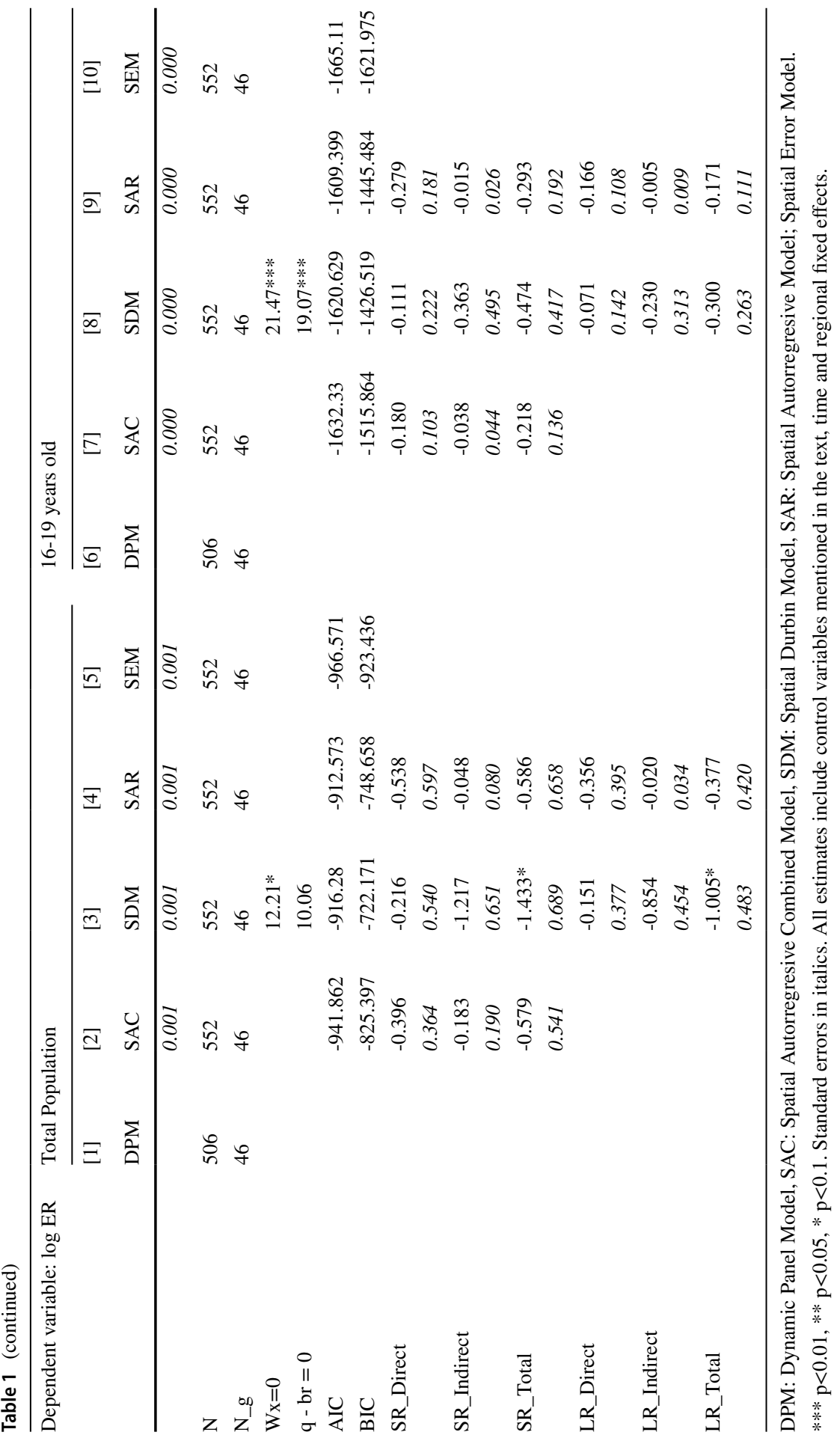


significant in the non-spatial model for this age-group, when considering different types of regional spillovers, a negative and statistically significant relationship emerges between employment rates and minimum wages. The elasticity is much higher than the value observed in the international literature for this specific group, although relatively close to estimates for this age group by Laporsek (2013) when considering 14 EU countries between 1996 and 2008. He finds an elasticity of -1.9 while our estimates are around -2.5 . This higher elasticity found for the Spanish economy can be potentially explained by the high increase of the Kaitz index during the Great Recession (as a result of the internal devaluation policy adopted by the Spanish Government), but also by the lower geographical mobility of youth in Spain when compared to other EU countries. Last, it is worth mentioning that, as in Kalenkoski and Lacombe (2018), the value of the elasticity increases after controlling for spatial dependence. These authors found an elasticity of teen employment to minimum wages of -0.18 when estimating a standard panel data model with state- and year-fixed effects, a value that increased up -0.21 when considering spatial dependence, a larger estimate because it includes both direct and indirect effects. So, the obtained evidence confirms the need to consider spatial interactions when analysing the relationships between minimum wages and employment rates in order to avoid potential biases that could seriously affect the conclusions from the empirical analysis Fig. 4, 5, 6 and 7.

\section{Final remarks}

In this paper, we have analysed the effect of minimum wages on total and youth employment in Spain taking into account the potential presence of spatial dependence in the considered relationship, an aspect that has been systematically neglected in the literature.

The analysis for the Spanish provinces is particularly interesting due to the low level of interregional mobility but also due to the high increase in the minimum wage during the recession and the high level of interregional heterogeneity in the Kaitz index.

Descriptive evidence shows a negative relationship between the Kaitz index and the employment rate that, however, is not confirmed in most cases when dynamic panel data including spatial spillovers are considered. In fact, our analysis confirms the need to take into account spatial interactions between regional labour markets, but it also shows that the bias of neglecting the existence of spatial spillovers could act in different directions as we have found that an initial negative effect of minimum wage on employment rates for youth aged 24-29 turned out to be non-statistically significant in spatial models, but an opposite result for those youth aged 16-19.

From a policy perspective, the obtained evidence suggests that for the considered period (2006-2018), minimum wages in Spain seem to be at a level that were not damaging overall employment creation, but it has substantially affected those youth aged between 16 and 19 years. The results are well in line with those obtained by Barceló et al. (2021) using microsimulation methods and analysing the increases of the minimum wage in 2017 and in 2019 (not considered in our work). They found 
that around $20 \%$ of workers aged 16-24 were affected by these measures and that the probability of losing their job among those directly affected by the measure increased between 6 and 11 percentage points. As Barceló et al. (2021) recognise, the analysis of the impacts of minimum wages should not only focus on employment variation. Looking at what has been the effect on wage inequality and low-paid jobs is also an important part of the story that should be considered in the policy debate. Last, it is also worth mentioning that our analysis (but also Barceló et al., 2021) do not consider the potential impact of minimum wage changes on participation decisions, an issue that deserves future analysis as it also clearly relevant from a policy perspective.

\section{Appendix}

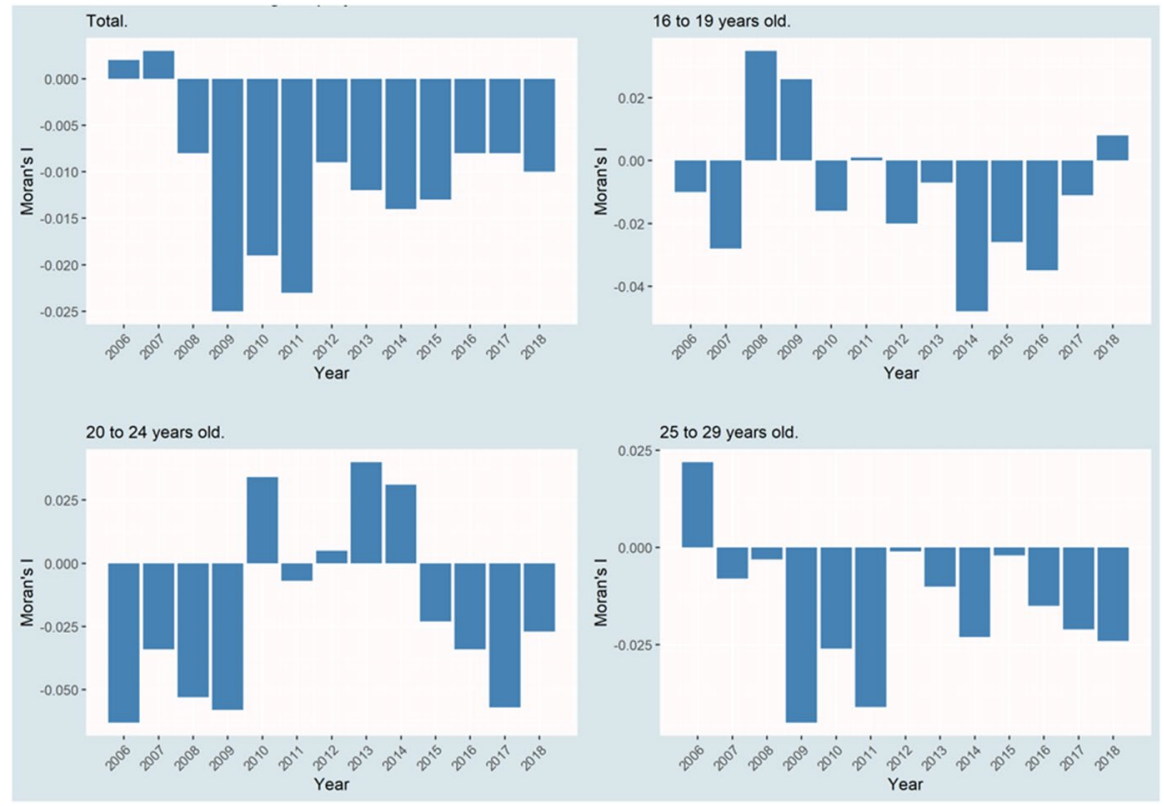

Fig. 4. Global Moran's I for the log of Employment Rate Inverse of distance spatial matrix 


\section{a) Total Population}

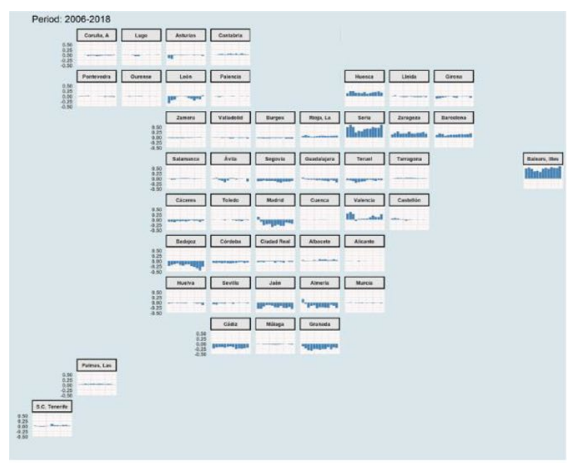

c) Youth 20-24

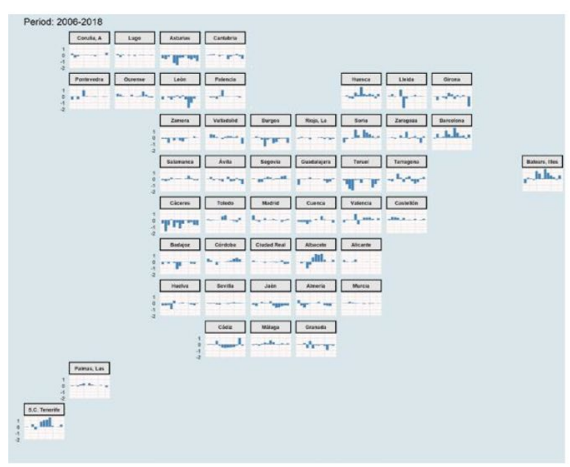

b) Youth 16-19

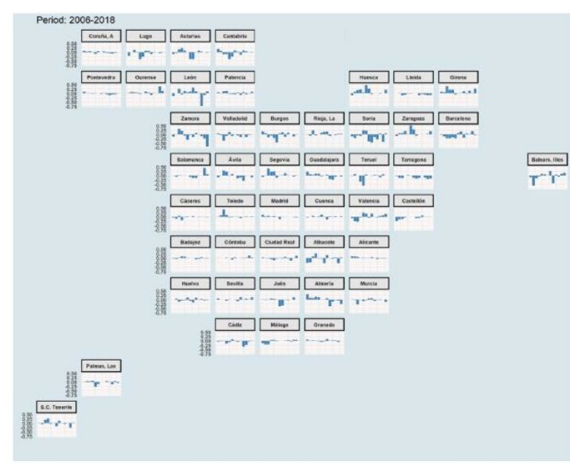

d) Youth 25-29

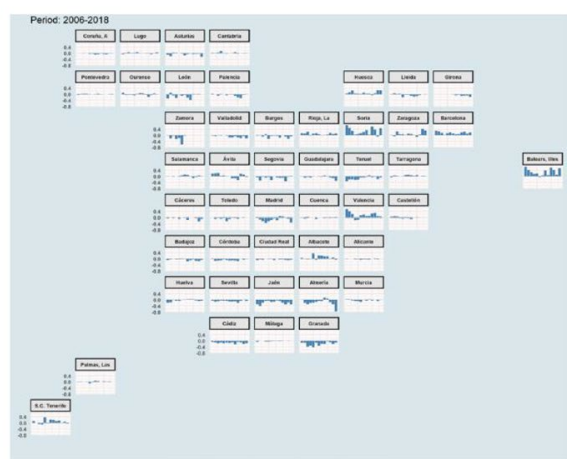

Fig. 5 Local Moran's I for the log of Employment Rate Inverse of distance spatial matrix a) Total Population b) Youth 16-19 c) Youth 20-24 d) Youth 25-29 

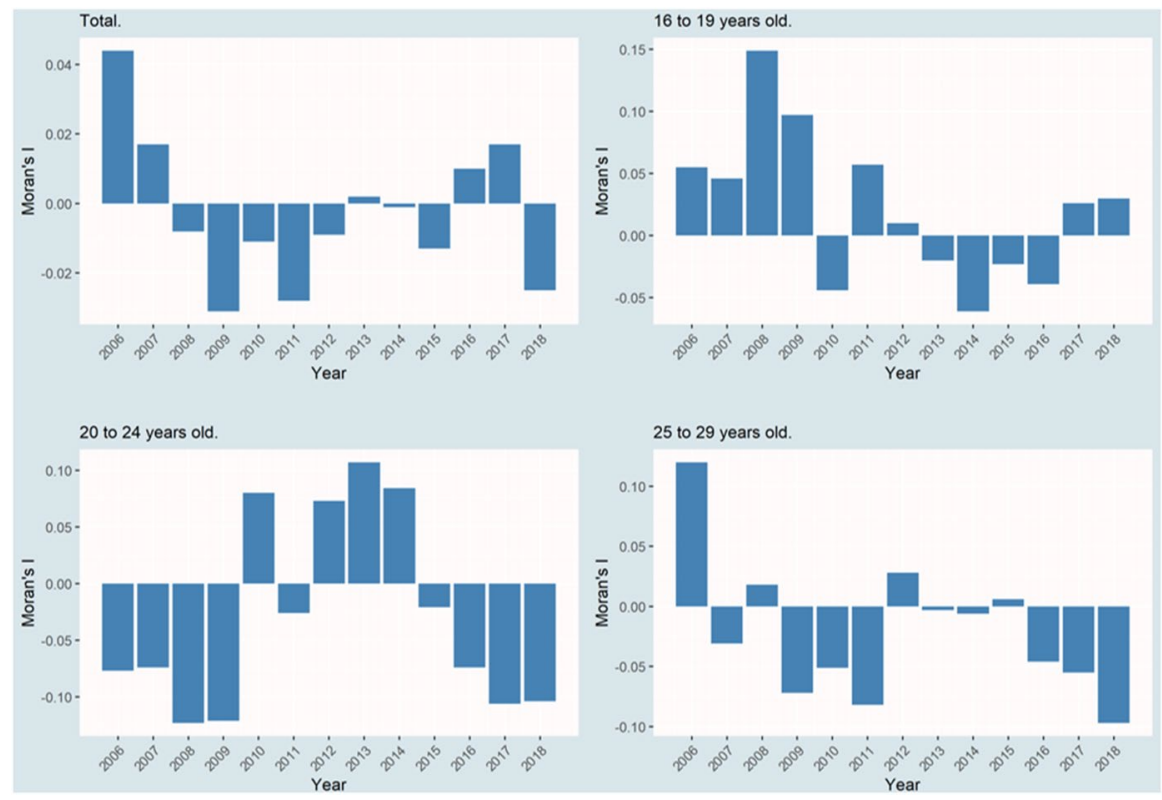

Fig. 6. Global Moran's I for the log of Employment RateKnn(5) spatial matrix 


\section{a) Total Population}

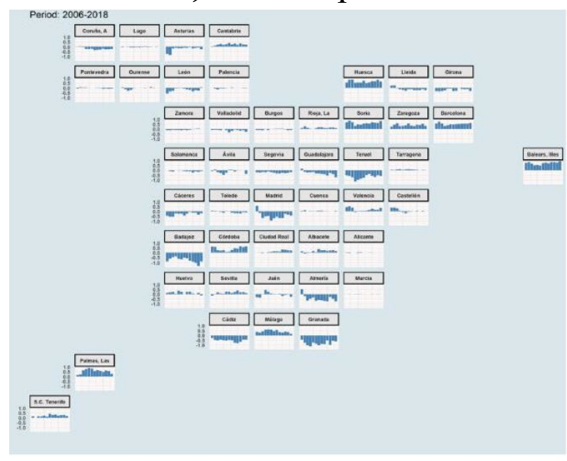

c) Youth 20-24

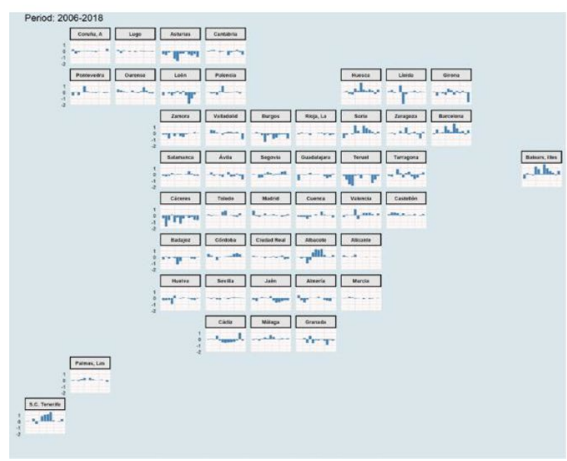

b) Youth 16-19

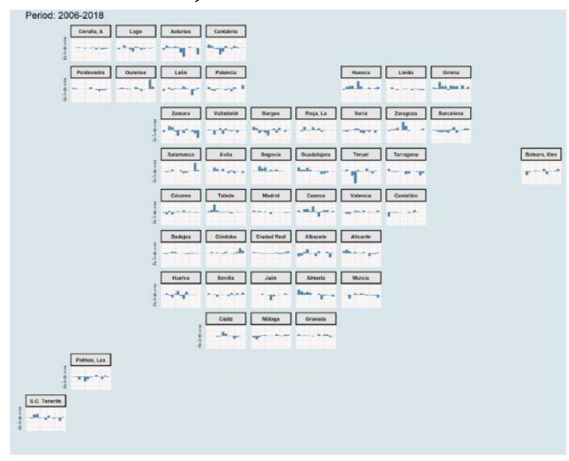

d) Youth 25-29

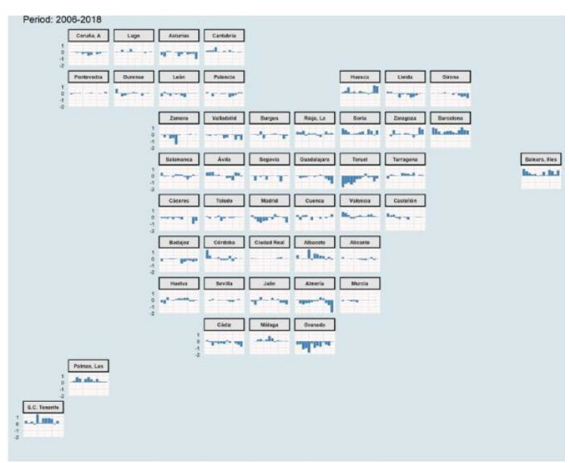

Fig. 7 Local Moran's I for the log of Employment Rate Knn(5) spatial matrix a) Total Population b) Youth 16-19 c) Youth 20-24 d) Youth 25-29 


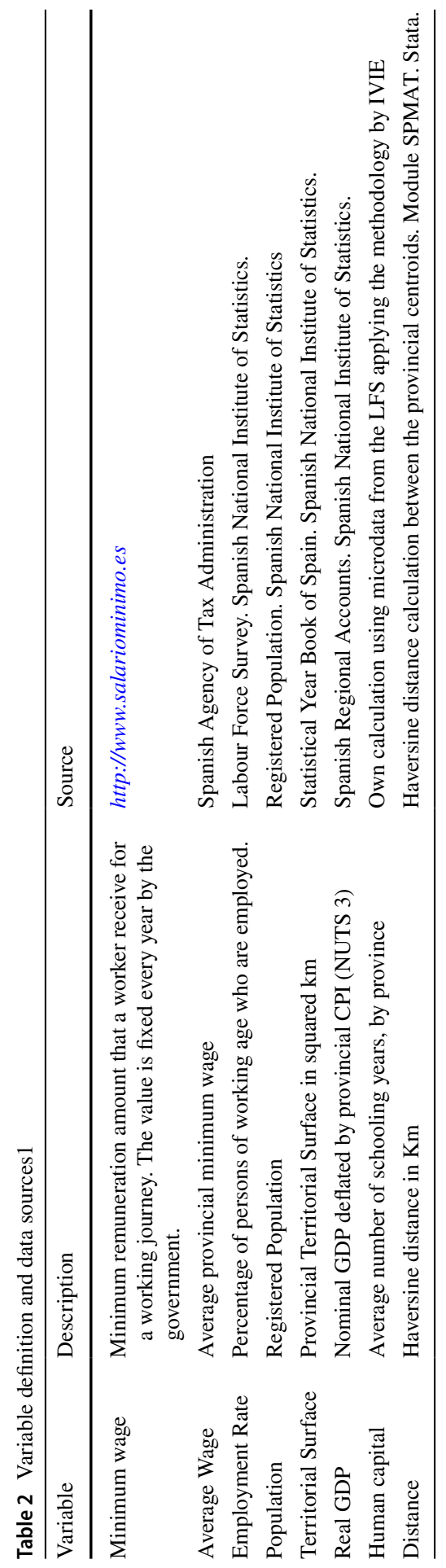


Table 3 Descriptive statistics 2006-2018

\begin{tabular}{llllll}
\hline & Employment Rate & $\begin{array}{l}\text { Youth Employ- } \\
\text { ment Rate } \\
(16-19)\end{array}$ & $\begin{array}{l}\text { Youth Employ- } \\
\text { ment Rate } \\
(20-24)\end{array}$ & $\begin{array}{l}\text { Youth Employ- } \\
\text { ment Rate } \\
(25-29)\end{array}$ & Kaitz Index \\
\hline Mean & 64.10 & 13.81 & 45.81 & 70.57 & 53.66 \\
St. Dev. & 5.78 & 8.56 & 12.49 & 8.48 & 8.17 \\
CV & 0.09 & 0.62 & 0.27 & 0.12 & 0.15 \\
Min & 48.89 & 2.03 & 21.66 & 50.13 & 35.39 \\
Max & 74.81 & 40.65 & 68.49 & 87.13 & 76.60 \\
Range & 25.91 & 38.61 & 46.83 & 37.00 & 41.21 \\
p25 & 60.24 & 6.05 & 35.55 & 65.11 & 48.01 \\
p50 & 64.36 & 11.70 & 47.58 & 71.33 & 52.28 \\
p75 & 69.47 & 19.15 & 56.43 & 78.31 & 58.96 \\
\hline
\end{tabular}




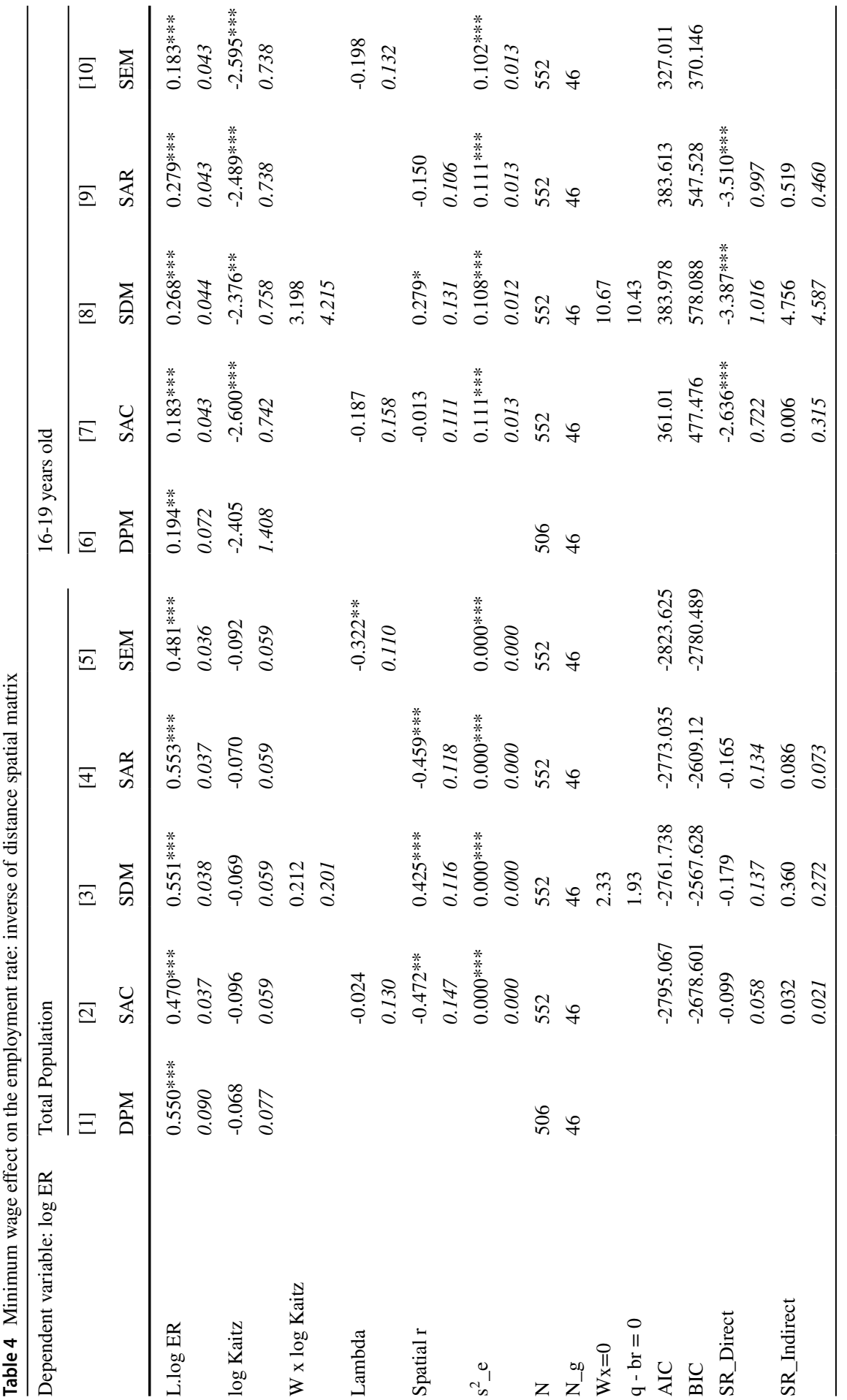




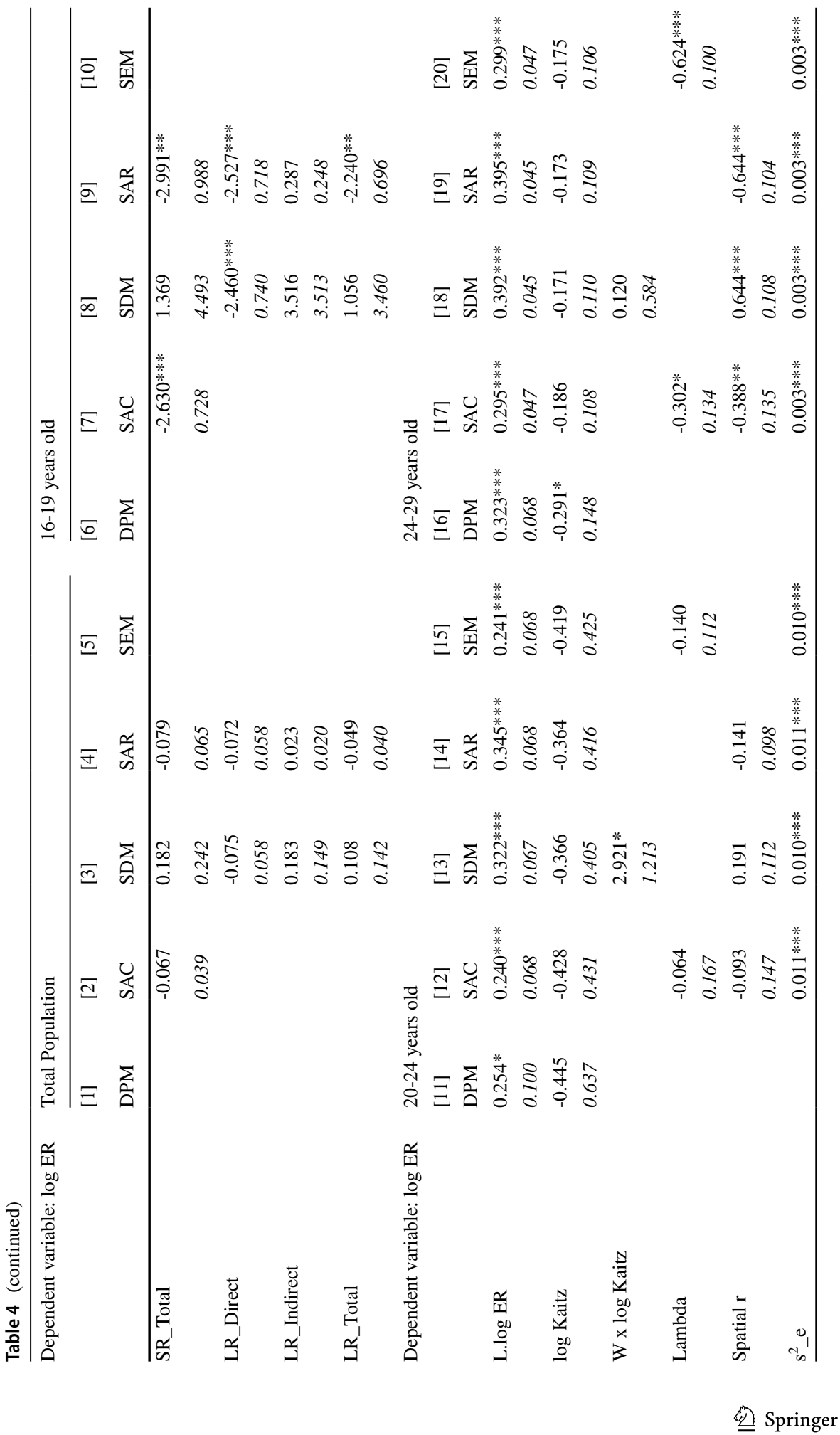




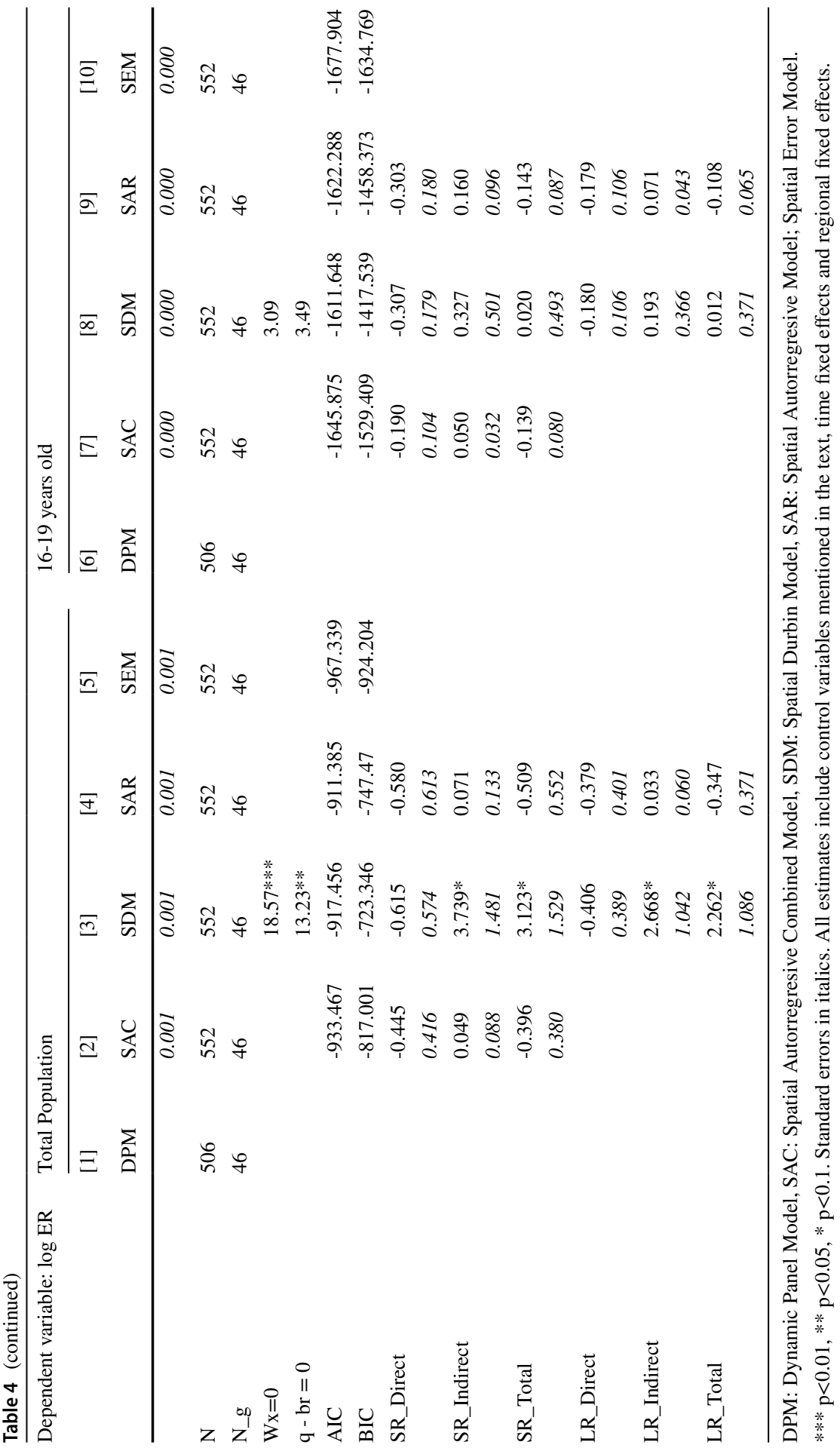




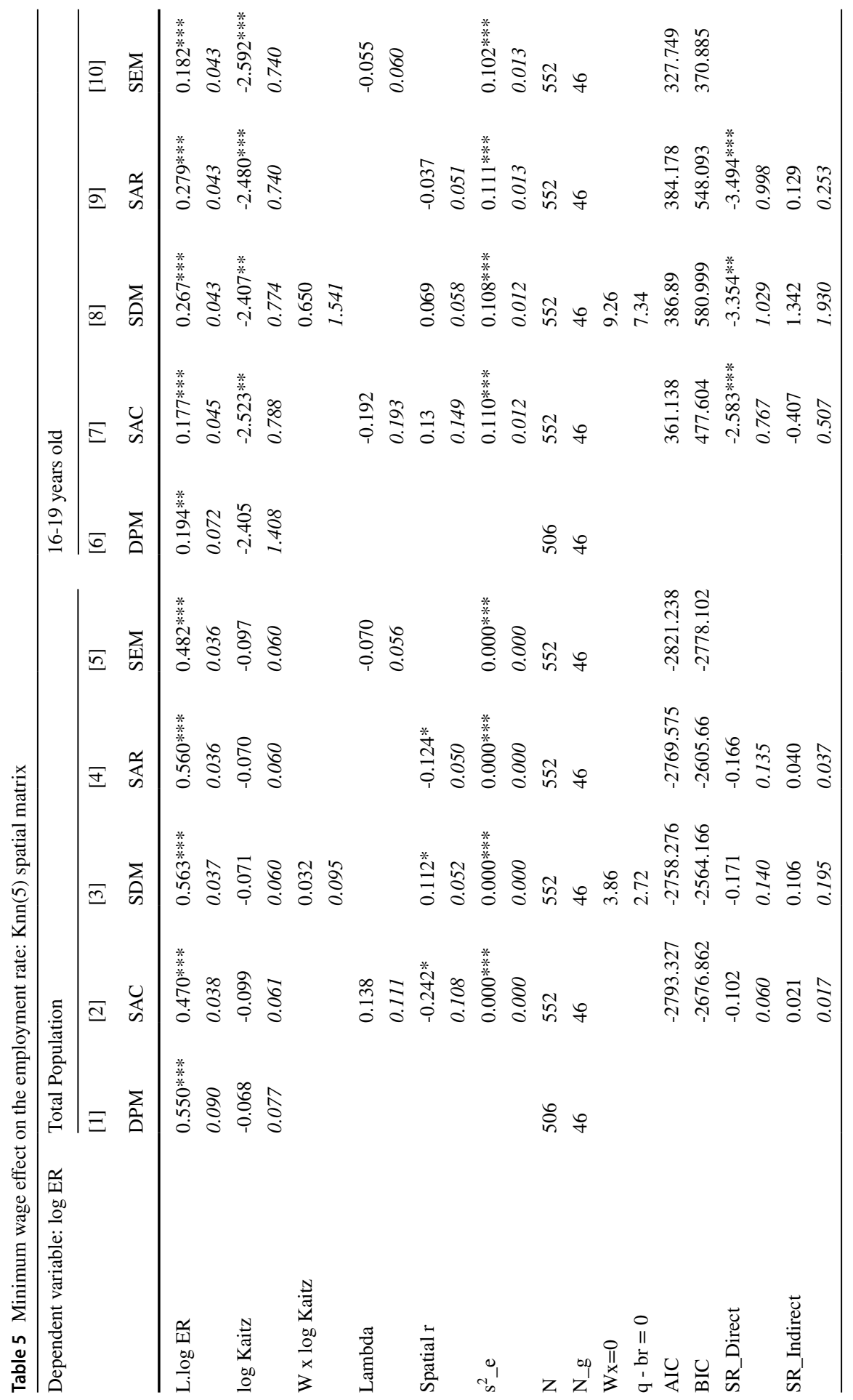




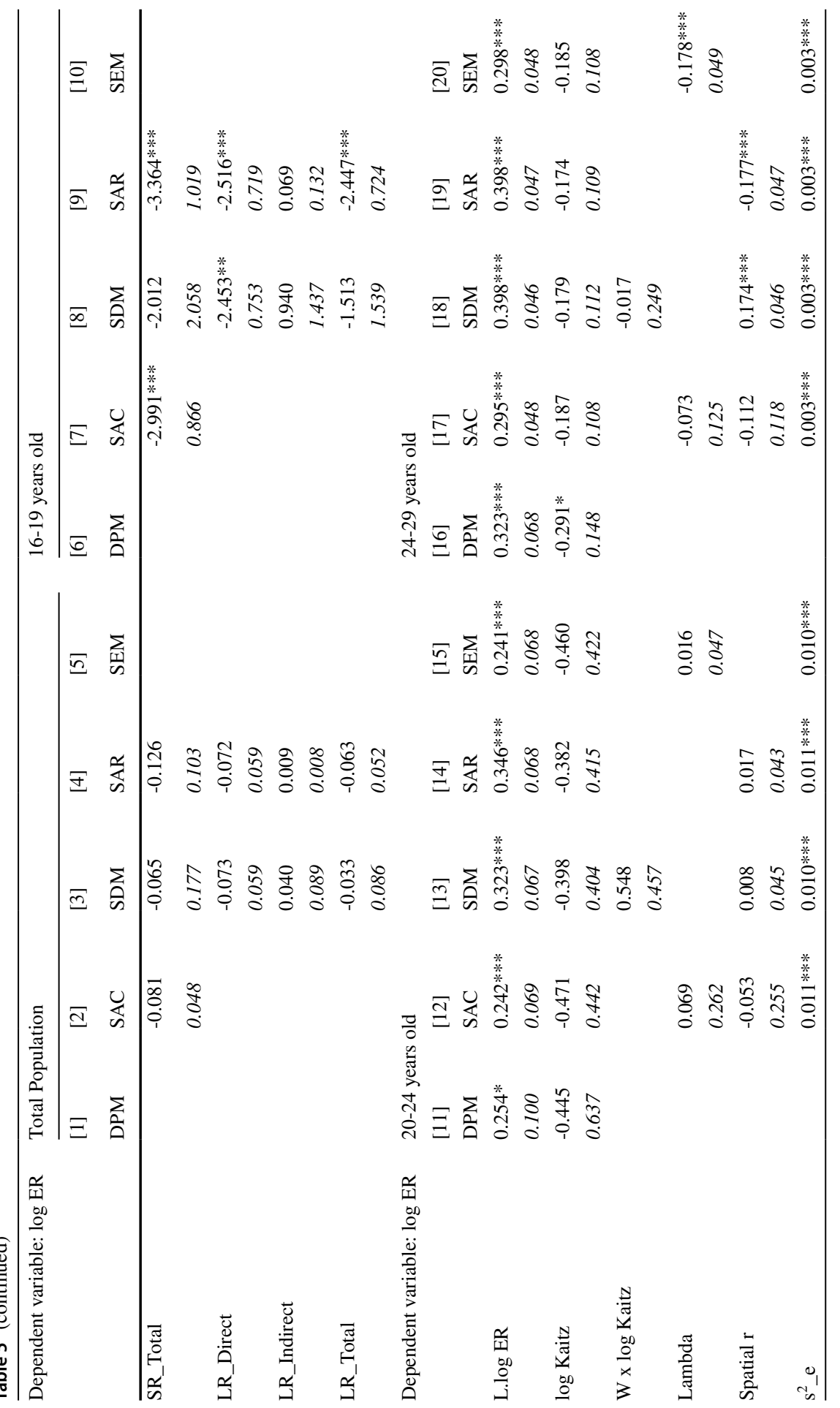

\section{旬 Springer}




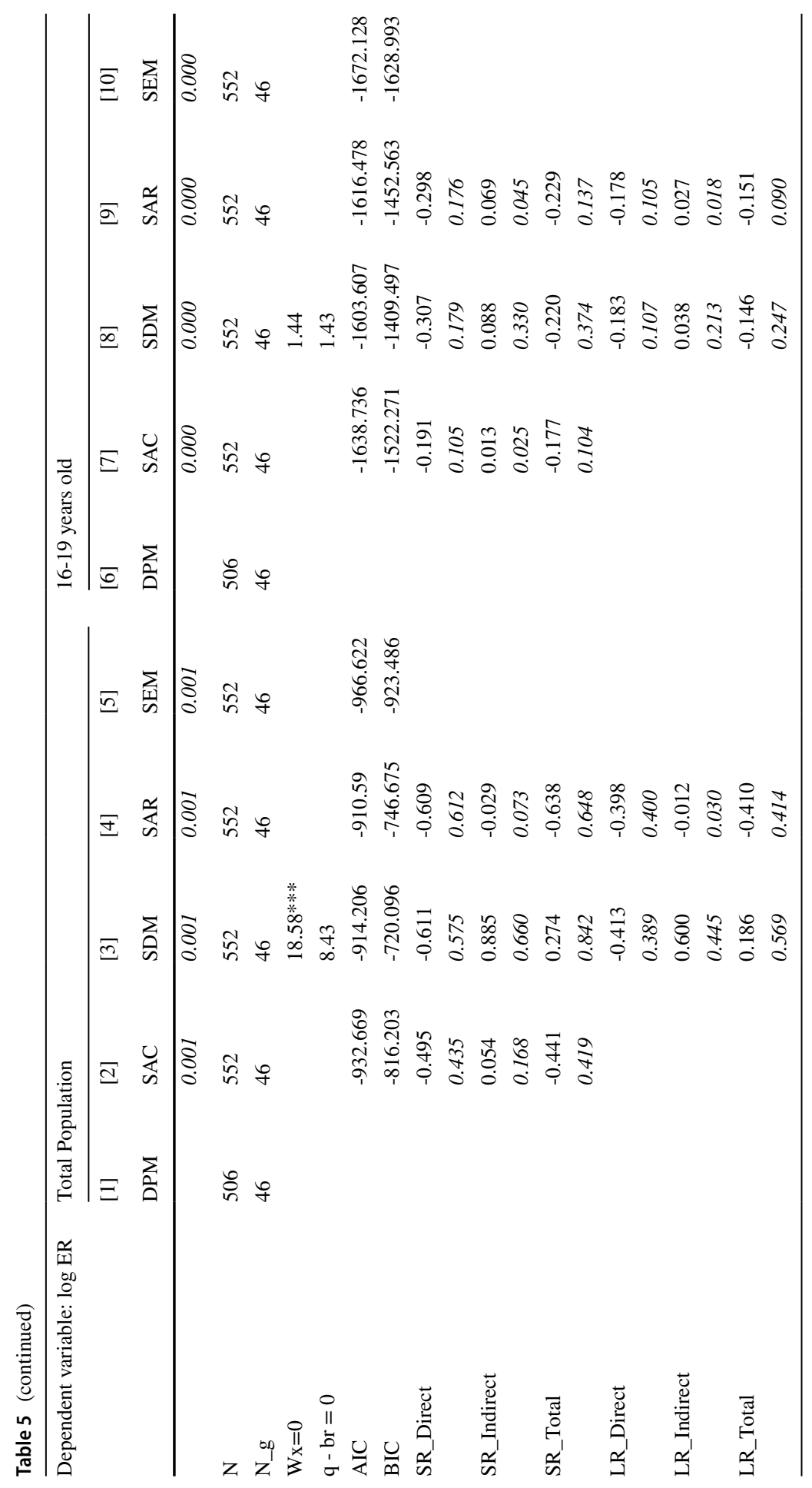

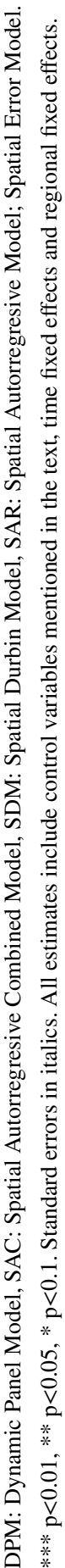


Acknowledgements The authors would like to express their gratitude to an anonymous referee and to the editor for their useful comments and suggestions. The usual disclaimer applies. Raul Ramos acknowledges the support received from the Agencia Estatal de Investigación (AEI - 10.13039/501100011033) through project PID2020-118800GB-I00.

Funding Open Access funding provided thanks to the CRUE-CSIC agreement with Springer Nature.

Open Access This article is licensed under a Creative Commons Attribution 4.0 International License, which permits use, sharing, adaptation, distribution and reproduction in any medium or format, as long as you give appropriate credit to the original author(s) and the source, provide a link to the Creative Commons licence, and indicate if changes were made. The images or other third party material in this article are included in the article's Creative Commons licence, unless indicated otherwise in a credit line to the material. If material is not included in the article's Creative Commons licence and your intended use is not permitted by statutory regulation or exceeds the permitted use, you will need to obtain permission directly from the copyright holder. To view a copy of this licence, visit http://creativecommons.org/licen ses/by/4.0/.

\section{References}

Anselin, L. (2003). Spatial externalities, spatial multipliers and spatial econometrics. Int Regional Sc Rev, 26, 153-166.

Arpaia, A., Cardoso, P., Kiss, A., Van Herck, K., Vandeplas, A. (2017). Statutory Minimum wages in the EU: Institutional settings and macroeconomic implications. IZA Policy Papers 124.

Bande, R., \& Martín-Román, Á. (2018). Regional differences in the Okun's Relationship: New Evidence for Spain (1980-2015). Investigaciones Regionales-Journal of Regional Research, 41, 137-165.

Barceló, C., Izquierdo, M., Lacuesta, A., Puente, S., Regil, A., Villanueva, E. (2021). Los efectos del salario mínimo interprofesional en el empleo: Nueva evidencia para España, Banco de España, Documentos Ocasionales 2113.

Bellman, D., \& Wolfson, P. (2014). What does the minimum wage do? Upjohn Institute.

Boockmann, B. (2010). The Combined Employment Effects of Minimum Wages and Labor Market Regulation: A Meta-Analysis. Institute for Applied Economic Research Working Paper 65.

Card, D., \& Krueger, A. B. (1995). Myth and measurement: The new economics of the minimum wage. Princeton University Press.

Cebrián, I., Pitarch, J., Rodríguez, C., \& Toharia, L. (2010). Análisis de los efectos del salario mínimo sobre el empleo de la economía espanyola. Revista de Economía Laboral, 7, 1-38.

Costa, A., García, J, López, X, Raymond, J. L. L. (2015). Estimació de les paritats de poder adquisitiu per a les comunitats autònomes espanyoles. Monografies. Departament d'Economia i Coneixement. Generalitat de Catalunya.

Costa, A, García, J., Raymond, J. L. L., Sánchez-Serra, D. (2019). "Subnational purchasing power of parity in OECD countries: Estimates based on the Balassa-Samuelson hypothesis", OECD Regional Development Working Papers, No. 2019/12, OECD Publishing, Paris, https://doi.org/10.1787/3d8f5 f51-en.

Cuéllar-Martín, J., Martín-Román, Á. L., \& Moral, A. (2019). An empirical analysis of natural and cyclical unemployment at the provincial level in Spain. Applied Spatial Analysis and Policy, 12(3), 647-696.

Dolton, P., \& Rosazza-Bondibene, C. (2012). The international experience of minimum wages in an economic downturn. Econ Policy, 27(69), 99-142.

Doucouliagos, H., \& Stanley, T. D. (2009). Publication selection bias in minimum-wage research? A meta-regression analysis. Brit J Ind Relat, 47(2), 406-428.

Drukker, D., Peng, H., \& Prucha, I. R. (2013). Creating and managing spatial-weighting matrices with the spmat command. The Stata Journal, 13(2), 242-286.

Dube, A. (2019). Impacts of minimum wages: review of the international evidence, Report for HM Treasury and the UK Department for Business, Energy \& Industrial Strategy. 
Dube, A., Lester, T., \& Reich, M. (2010). Minimum wage effects across state borders: estimates using contiguous counties. Review of Economics and Statistics, 92(4), 945-964.

Elhorst, J. P. (2014). Spatial Panel Models. In M. Fischer \& P. Nijkamp (Eds.), Handbook of Regional Science. Springer.

Fingleton, B. (2008a). A generalized method of moments estimator for a spatial model with moving average errors, with application to real estate prices. Empir Econ, 34, 35-57.

Fingleton, B. (2008b). A generalized method of moments estimator for a spatial panel model with an endogenous spatial lag and spatial moving average errors. Spat Econ Anal, 3, 27-44.

Galán, S., \& Puente, S. (2015). Minimum wages: Do they really hurt young people? The BE Journal of Economic Analysis and Policy, 15(1), 299-328.

Holtemöller, O., \& Pohle, F. (2019). Employment effects of introducing a minimum wage: The case of Germany. Econ Model. https://doi.org/10.1016/j.econmod.2019.10.006

Kaitz, H. (1970). Experience of the past: The national minimum. youth unemployment and minimum wages. US Bureau of Labor Statistics Bulletin, 1657, 30-54.

Kalenkoski, C. (2016). The effects of minimum wages on youth employment and income, IZA World of Labor 243.

Kalenkoski, C. M., \& Lacombe, D. J. (2008). Effects of minimum wages on youth employment: The importance of accounting for spatial correlation. Journal of Labour Research, 29, 303-317.

Kalenkoski, C. M., \& Lacombe, D. J. (2013). Minimum wages and teen employment: A spatial panel approach. Pap Reg Sci, 92(2), 407-417.

Laporsek, S. (2013). Minimum wage effects on youth employment in the European Union. Appl Econ Lett, 20(14), 1288-1292.

LeSage, J. P., \& Pace, R. K. (2007). A matrix exponential spatial specification. J Econometrics, 140, 190-214.

Leonard, M. L., Stanley, T. D., \& Doucouliagos, H. (2014). Does the UK minimum wage reduce employment? A meta-regression analysis. International Journal of Employment Relations, 52(3), 499-520.

López-Bazo, E., Barrio, T. D., \& Artis, M. (2002). The regional distribution of Spanish unemployment: A spatial analysis. Papers in Regional Science, 81(3), 365-389.

López-Bazo, E., Barrio, T. D., \& Artís, M. (2005). Geographical distribution of unemployment in Spain. Regional Studies, 39(3), 305-318.

López-Bazo, E., \& Motellón, E. (2012). Human capital and regional wage gaps. Regional Studies, 46(10), 1347-1365.

Majchrowska, A., \& Strawiński, P. (2018). Impact of minimum wage increase on gender wage gap: Case of Poland. Econ Model, 70, 174-185.

Martín-Román, Á. L., Cuéllar-Martín, J., \& Moral, A. (2020). Labor supply and the business cycle: The "Bandwagon Worker Effect". Papers in Regional Science, 99(6), 1607-1642.

Mota, P. R., Varejão, J., \& Vasconcelos, P. B. (2012). Hysteresis in the dynamics of employment. Metroeconomica, 63, 661-692.

Mur, J., \& Angulo, A. (2006). The spatial Durbin model and the common factor test. Spat Econ Anal, $1,207-226$.

Neumark, D., \& Wascher, W. (2004). Minimum wages, labor market institutions and youth employment: A cross-national analysis. Ind Labor Relat Rev, 57(2), 223-248.

O’Higgins, N., Moscariello, V. (2017). Labour market institutions and youth labour markets: Minimum wages and youth employment revisited, ILO Working Paper 223.

Porras-Arena, M. S., \& Martín-Román, Á. L. (2019). Self-employment and the Okun's law. Economic Modelling, 77, 253-265.

Ramos, R., \& Royuela, V. (2017). Graduate migration in Spain: the impact of the Great Recession on a low-mobility country. In J. Corcoran \& A. Faggian (Eds.), Graduate Migration and Regional Development. Edwar Elgar Publishing.

Rybczynski, K., \& Sen, A. (2018). Employment effects of the minimum wage: panel data evidence from Canadian provinces. Contemp Econ Policy, 36(1), 116-135.

Schmitt, J. (2013) Why does the minimum wage have no discernible effect on employment?, CEPR Working Paper 2.

Publisher's Note Springer Nature remains neutral with regard to jurisdictional claims in published maps and institutional affiliations. 